\title{
Prevention of Work-Related Falling/Slipping Accidents in Taiwan
}

\author{
Kai Way LI \\ Department of Industrial Management, Chung-Hua Polytechnic Institute
}

\begin{abstract}
Prevention of Work-Related Falling/ Slipping Accidents in Taiwan: Kai Way Lı. Department of Industrial Management. Chung-Hua Polytechnic Institute - The prevention of slipping and falling accidents in the workplace has received very limited attention in Taiwan. Official statistics on work-related falling accidents in 1994 revealed that subsequent losses from those accidents were significant. The R.O.C. Institute of Occupational Safety and Health (IOSH) recently recommended that safety footwear be worn in certain private sectors, but standards governing the slip-resistance of sole materials for safety footwear have not yet been established. In this study, a Chung-Hua Polytechnic Institute machine is designed and fabricated to measure the friction coefficients of shoes, floor, and contamination combinations. A model to continuously improve work place safety is also presented to reduce the risk of slipping/falling accidents.

(J Occup Health 1997; 39: 75-79)
\end{abstract}

Key words: Slipping/falling accidents, Coefficient of friction, Footwear, Floors

Falling on the same or different levels is one of the primary causes of occupational deaths and injuries in Taiwan. Falling may be caused by slipping or tripping. Tripping occurs when the walker's foot is obstructed by unexpected objects on the floor. Slipping occurs when the friction is insufficient to resist the sliding motion of the shoe on the walkway surface. Slipping may occur immediately after the leading foot lands on the floor or before the rear foot takes off. The backward slipping motion of the rear foot at take-off normally causes no serious problem because the body weight is transferring away from the rear foot to the leading foot. The forward

Received Dec 22, 1995; Accepted July 30, 1996

Correspondence to : $K . W . L i$. Department of Industrial Management, Chung-Hua Polytechnic Institute, 30 Tung-Shiang, HsinChu, Taiwan slipping motion of the leading foot when landing is hazardous if the heel accelerates forward to a velocity greater than the velocity of the center of gravity of the body. When this occurs, the forward thrust of the foot on the floor continues to increase and subsequently leads to a loss of balance.

\section{Accidents in Taiwan}

Table 1 summarizes the number of work-related falling accidents in Taiwan in 1994 ${ }^{1)}$. 1,117 falling accidents occurred which accounts for $13.5 \%$ of all occupational mishaps. More than half of the accidents were reported by manufacturing industries, but Table 1 only accounts for a part of the situation. All business organizations are required by $\mathrm{law}^{2)}$ to establish an occupational safety department and/or personnel, record accidents in the workplace and report monthly to the Council for Labor Affairs. The statistics in Table 1 reflect only those which were reported. A recent investigation indicated that more than $60 \%$ of the small firms (having 30 employees or less) did not have safety personnal ${ }^{1)}$. Factory inspectors issued three hundred and eighty-one citations in 1994 to companies failing to report monthly. In addition, the accident classification system itself was incapable of accurately identifying many slipping accidents. Not surprisingly, an accident report involving the amputation of a hand in a moving blade may not mention the spilt sand in front of the machine which caused the original slip and the loss of balance. A worker who falls and is then struck by a moving vehicle may also be recorded as a traffic accident. The official numbers of accidents apparently underestimate the seriousness of the falling accidents.

Table 2 shows the numbers of fatalities and injuries in 1994 reported by the Labor Insurance Bureau (LIB) of the R.O.C. ${ }^{1)}$ 3,884 injuries, 125 permanent disabilities, and 236 deaths occurred in all the occupations. These numbers, however, did 
Table 1. Number of work-related falling accidents

\begin{tabular}{lc}
\hline Sector of employment & Number of accidents \\
\hline Agriculture & 3 \\
Mining & 22 \\
Manufacturing & 685 \\
Utilities & 17 \\
Construction & 47 \\
Commerce & 31 \\
Transportation & 262 \\
Business service & 50 \\
Total & 1,117 \\
\hline
\end{tabular}

Table 2. Outcomes of falling accidents

\begin{tabular}{lrrr}
\hline $\begin{array}{c}\text { Sector of } \\
\text { employment }\end{array}$ & Injuries & $\begin{array}{c}\text { Permanent } \\
\text { disability }\end{array}$ & Death \\
\hline Agriculture & 46 & 1 & 13 \\
Mining & 26 & 1 & 1 \\
Manufacturing & 1,329 & 37 & 53 \\
Utilities & 10 & 0 & 0 \\
Construction & 1,712 & 48 & 119 \\
Commerce & 267 & 8 & 20 \\
Transportation & 314 & 17 & 14 \\
Business service & 180 & 13 & 16 \\
Total & 3,884 & 125 & 236 \\
\hline
\end{tabular}

Table 3. Percentage of body parts injured

\begin{tabular}{lc}
\hline \multicolumn{1}{c}{ Body part } & Percentage $(\%)$ \\
\hline Head/neck & 17.2 \\
Chest/abdomen & 8.3 \\
Shoulder/back/bottom & 13.3 \\
Internal organs & 0.9 \\
Upper/lower arm & 4.2 \\
Wrist/hand & 13.9 \\
High/knee/lower leg & 20.5 \\
Ankle/foot & 18.0 \\
Not stated & 3.7 \\
\hline
\end{tabular}

not capture public attention even though they exceeded the numbers of many diseases (e.g. AIDS) and catastrophes (e.g. fire accidents and crash of a jumbo jet). LIB has paid over 320 million New Taiwan Dollars in compensation and medical expense to the victims. Moreover, the financial and social losses suffered by the employers, the victims, and their families were enormous.

Table 3 lists the percentages of body parts injured in industrial falling accidents. This table reveals that more than a third of the injuries were detected in the lower extremities. This finding corresponded to a similar observation by Manning and his colleagues $^{3)}$ that ankles and knees are the most fre- quently injured body parts. Upper extremity and head/neck injuries were also found to be common results of falling accidents.

\section{Accident Prevention}

\section{1. Safety footwear}

Manning et al. ${ }^{3)}$ reported that around $45 \%$ of the so-called 'underfoot accidents' in their study might have been prevented if slip-resistant footwear was used. Strandberg and Lanshammar ${ }^{4)}$ and Proctor and Coleman ${ }^{5)}$ suggested that dynamic drainage properties of footwear should be carefully assessed. The sole should be capable of establishing a 2 or 3 $\mu \mathrm{m}$ thick hydrodynamic film of water. The R.O.C. Institute for Occupational Safety and Health (IOSH) has recently published an Occupational Safety Footwear Handbook ${ }^{6)}$. The slip-resistance of sole material is one of the functional requirements addressed in the handbook. The denotation of slipresistance is, however, unspecified. The CNS (Chinese National Standards) standard for the slipresistance of safety footwear has also not yet been established.

\section{2. Coefficient of friction measurement}

The absence of slip-resistance on the walking surface accounts for slipping of the foot. The slipresistance of the floor can be assessed by the coefficient of friction (COF). COF is defined as the ratio of horizontal force to vertical force on the contacted surface. It can be measured statically or dynamically. Static COF is the ratio which is just sufficient to cause a sliding movement on the surface. Dynamic COF is the same ratio measured when one surface is sliding over another.

Some investigators ${ }^{7,8)}$ suggested that good static slip-resistant qualities are the most important prerequisite for sole and floor materials. The main reason for this is that static COF determines whether a slip will be initiated or not. A static COF of 0.5 has been accepted as a safety limit for walking on a level surface in the United States ${ }^{9}$. Although static COF has been used for years, its utility is still doubted by others. Strandberg ${ }^{10)}$, for example, proposed that the dynamic slip-resistance for the rear-edge of the heel is most important for fall prevention because it determines whether a slip will continue or not. If a slip is stopped right after it has started, it probably would not cause any problem.

To measure COF, many measuring devices have been developed. These devices were based on three approaches ${ }^{11}$. First, pulling or pushing an instrumented burden across the surface; second, allowing a pendulum to strike the test surface, and 


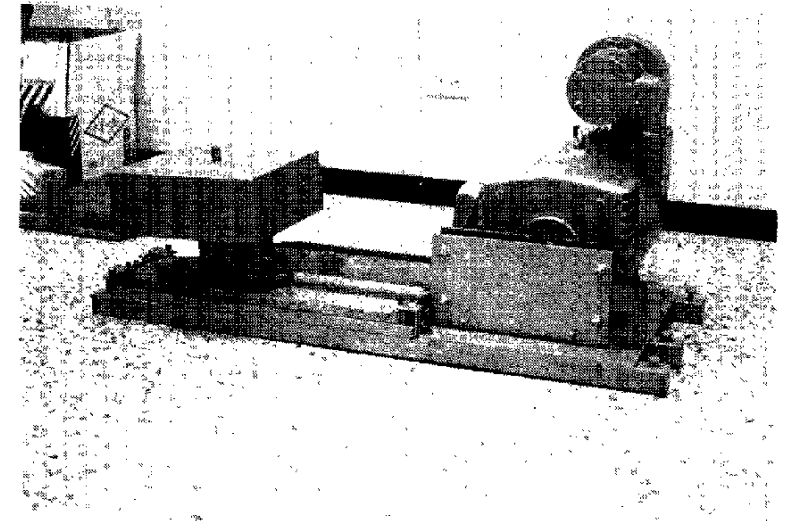

Fig. 1. CHPI machine for the determination of COF.

finally, displacing an articulated strut. Examples of these devices have been reported by many investigators ${ }^{9,12-16)}$. Some of the devices have been evaluated by Andres and Chaffin ${ }^{17}$. In Taiwan, a Chung-Hua Polytechnic Institute (CHPI) machine was designed and built by the author ${ }^{18)}$ recently (Fig. 1). The machine design is not complex. The power is generated by a Dong-Yuan DC motor (GSCT 3HP) and controlled by a control panel to apply pressure on the steel testing foot. The horizontal force may be measured by a loadcell embedded in the connecting rod and read through a personal computer. The vertical force is generated by steel loads. COF is computed by the ratio of the measured horizontal force to the vertical force. Both static and dynamic COF can be measured.

The operating principle of the CHPI machine is relatively simple. It can be used to evaluate the slip resistance of sole materials and floor surfaces. The effects of different contaminants can also be determined. To operate, the sole material is attached to the bottom of the steel foot. A $590 \times 160 \mathrm{~mm}$ floor sample is mounted on the frame. A previous study demonstrated that dynamic COF varies with the load applied and the sliding velocity ${ }^{15}$. These parameters can be controlled when operating the machine. The maximal vertical loads can be $80 \mathrm{~kg}$, which is higher than the body weight of a normal Taiwanese person. The corresponding normal force generated is $784 \mathrm{~N}$. The maximal sliding velocity of the steel foot is $50 \mathrm{~cm} / \mathrm{sec}$. Strandberg and Lanshammar ${ }^{4)}$ indicated that slipping normally results in a fall if the sliding velocity exceeds 50 $\mathrm{cm} / \mathrm{sec}$.

\subsection{Improvement in work place safety}

The CHPI machine is not only a measuring tool, but was originally constructed to continuously improve workplace safety. Figure 2 shows a model aimed at achieving this goal. The model initially in-

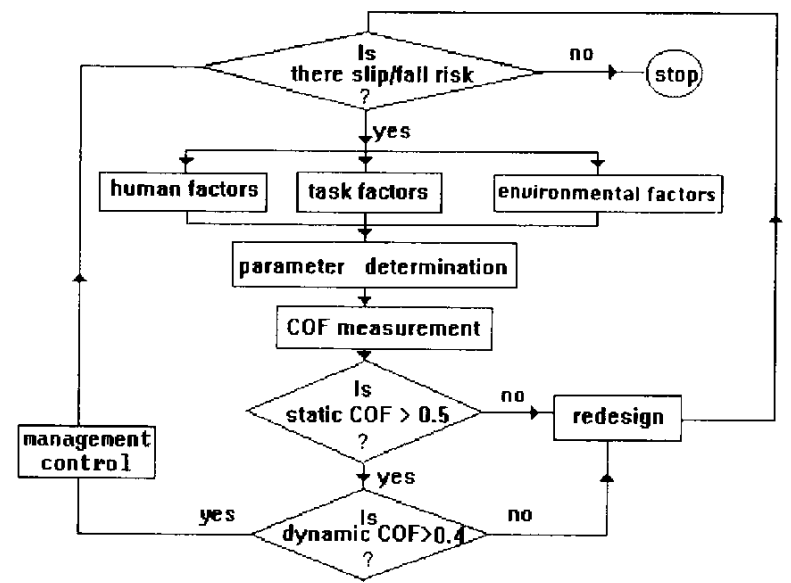

Fig. 2. Model to improve work place safety.

vestigates the risk of a fall. Such an investigation can be performed by checking the safety and health records in the organization. As already mentioned, many companies may not have or maintain such a record. Interviews with employees are therefore important. Employees generally have more information than any outsider, thereby making them the most reliable sources to provide significant data. If no risk of slipping/falling has been found, no action is deemed necessary. If a risk exists, investigating the factors related to individuals, tasks and the environment should be proceeded with.

The individual factors include body weight, gait pattern, and the psychophysical capacity of individuals. The task factors encompass the type and frequency of activities required to perform tasks. The environmental factors are floor materials, contaminations, lighting, stairs and layout of the work place.

For the purpose of simplification, only vertical loads and sliding velocity are needed to operate the CHPI machine. A COF measurement can be taken following the procedure mentioned in 2.2. Both static and dynamic COF should be determined for the sole material, floor, and contamination combinations. If either the static COF or dynamic COF fail to satisfy the 0.5 and 0.4 requirements, adopting more slip-resistant floor materials and/or slipresistant footwear should be considered. A slipresistant tape or mat may be beneficial in certain areas. The 0.5 and 0.4 requirements are the 'anti-slip' standards for static and dynamic COF in a walkway recommended by the American Society for Testing and Materials (ASTM) ${ }^{9)}$ and the British Standard Institution (BSI) ${ }^{19}$, respectively. If the COFs meet the upper limits, management control should be reinforced. Housekeeping is a conventional industrial safety practice. Responsibilities should be assigned to monitor floor conditions so 
that spillage, dust, and loose components can be removed immediately. A standard procedure for floor cleaning should be established and implemented. Scheduling of floor cleaning activities should be arranged so that those activities themselves will not block traffic flow and create a potential hazard to co-workers. Assessment of lighting and layout of work areas may also be introduced periodically to ensure that environmental risk is minimized.

In this article, we performed a study in the kitchens of two student dining halls at Chung-Hua Polytechnic Institute. The two dining halls daily serve the meals of more than four thousand students. Occupational safety records on campus have not yet been established. To identify the types of potential workplace hazards, the kitchen workers were interviewed. Nearly all of the workers in the first dining hall complained of the slippery kitchen floor. Roughly one third of the workers in the second dining hall also felt the floor was slippery. Further inquiry revealed that the first kitchen was surfaced with a smooth ceramic tile and the second kitchen was covered with a ceramic tile having octagonal projections. Food and cooking materials were occasionally spilled on the floors of both kitchens. The workers cleaned up the spillage by washing the floor with water whenever possible. A floor covered with vegetable oil and/or water during working hours was not an atypical situation. It was, therefore, decided that the coefficients of friction of the floors should be measured.

The workers wore plastic waterproof shoes when they worked. The same plastic material was then attached to the steel foot of the machine. A floor sample was prepared and tested for each type of tile used in the two kitchens. Measurements from five replications were recorded for each sample. External loads of $75 \mathrm{~kg}$ were imposed on the steel foot during the measurement to approximate the workers' body weights. The sliding velocity of the steel foot for dynamic measurement was $20 \mathrm{~cm} / \mathrm{sec}$. Table 4 presents the mean COF for the two samples

Table 4. Mean COF of the floor samples

\begin{tabular}{ccc}
\hline \multicolumn{1}{c}{ Floor sample } & Static & Dynamic \\
\hline Smooth ceramic & & \\
dry & 0.67 & 0.51 \\
wet & 0.49 & 0.37 \\
greased & 0.41 & 0.23 \\
Ceramic with octagonal projections & & \\
dry & 0.72 & 0.55 \\
wet & 0.51 & 0.42 \\
greased & 0.45 & 0.29 \\
\hline
\end{tabular}

under different conditions.

According to these results, for the smooth ceramic tile used in the first kitchen, both the static and dynamic COF were below the 0.5 and 0.4 limits for the wet and oil-contaminated conditions, respectively. For the ceramic tile used in the second kitchen, both the COF were also below the recommended limits under the greased condition. Improving the floor surface was therefore recommended. Many slip-resistant tiles are commercially available with various materials and surface geometries. Replacement of the tiles. however, was impossible due to the high cost and ease of cleaning. A slip-resistant mat $\left(64 \times 90 \mathrm{~cm}^{2}\right)$ with soft plastic projections (1 $\mathrm{cm}$ high) was then recommended and adopted. Covering the entire area of the kitchen was not deemed feasible because the cleaning task would become much more complicated. Only the washing-up area, cooking area and floor in front of the refrigerator were covered with the plastic mats because the floor in those areas became wet and/or spilled on more often than other areas. To assess whether an improvement had been made was not easy because of the lack of accident records on campus. The workers in both kitchens were interviewed again three weeks after the mats had been put into use. The majority of the workers felt that the slipperiness of the floor had been reduced, but some workers complained of having the added responsibility of cleaning the mats.

\section{Future Needs}

Occupational safety and health authorities in Taiwan have contributed little toward slip/fall prevention. The law requires that employers provide an anti-slip environment for employees ${ }^{2)}$, but 'anti-slip' is not clearly defined. Slip-resistance standards must therefore be established for floor materials to be used in work places and public areas. The slip-resistant qualities and geometric design of sole materials for safety footwear should also be investigated and standardized. Furthermore, more investigations should be performed concerning the environmental effects, in addition to contamination, on slipping and falling, for example how lighting affects human perception of floor slipperiness.

Assessing the slippery condition of a floor surface should be introduced for practioners to improve work place safety. A program of assessment should be established as a part of ordinary business operations. Such an assessment should consider many factors, such as specific activities involved in performing tasks. For instance, lifting, pulling, pushing and load carrying may alter the vertical force on the floor, thereby increasing the tendency to slip. 
These factors may also make it more difficult for a worker to handle a slip without receiving any injury.

Acknowledgment: The author would like to thank the National Science Council of the R.O.C. for financially supporting this study under contract No. NSC 83-0415-E216-002.

\section{References}

1) Council for Labor Affairs. 1994 Labor Inspection Annual Report, 1995 (in Chinese).

2) R.O.C. Governments. Labor Safety \& Health Law, port 1974, revised 1991 (in Chinese).

3) Manning DP, Ayers I, Jones C, Bruce M, Cohen $\mathbf{K}$. The incidence of underfoot accidents during 1985 in a working population of 10,000 Merseyside people. Journal of Occupational Accidents 1988; 10: 121130.

4) Strandberg L, Lanshammar $H$. The dynamics of slipping accidents. Journal of Occupational Accidents 1981; 3: 153-162.

5) Proctor TD, Coleman V. Slipping, tripping, and falling accidents in Great Britain - present and future. Journal of Occupational Accidents 1988; 9: 269-285.

6) Institute of Occupational Safety and Health. Occupational Safety Footwear Handbook. 1995: 5-18 (in Chinese).

7) Redfern MS, Adams PS. The effect of vertical force on static coefficient of friction. Proceedings of the Annual Conference of the Human Association of Canada, 1988: 161-164.

8) Perkins PJ. Measurements on slip between the shoe and the ground during walking. In: Andersson C, Senne J, eds. Walkway surfaces: measurement of slip resistance. ASTM STP 649, 1978: 71-87.

9) American Society for Testing and Materials. Designation D 2047-75, Standard method of test for static coefficient of friction of polish-coated floor surfaces as measured by James machine, Philadelphia : 1975.

10) Standberg L. On accidents analysis and slipresistance measurement. Ergonomic 1983; 11-31.

11) Brungraber RJ. An overview of floor slip-resistance research with an annotated bibliography. U.S. Department of Commerce, NBS, Technical Note 895, January 1976.

12) Pooley RW. Measurement of frictional property of footwear sole and heel materials. In: Andersson C, Senne J, eds. Walkway surface: measurement of slip resistance. ASTM STP 649, 1978: 11-20.

13) Tisserand $M$. Progress in the prevention of falls caused by slipping. Ergonomics 1985,28 : 1027-1942.

14) Grönqvist R, Roine J, Jarvinen E, Korhonen E. An apparatus and a method for determining the slip resistance of shoes and floors by simulation of human foot motions. Ergonomics 1989; 32: 979-995.

15) Perkins PJ. Wilson, MP. Slip resistance rating of shoe-New development. Ergonomic 1983; 26: 73-82.

16) Buntergchit $Y$. Measurement of dynamic friction available between shoes and floors, appropriate to friction demands in walking. $\mathrm{Ph}$. D. thesis. Center for Safety Science, University of New South Wales, Australia, 1990.

17) Andres RO, Chaffin DB. Ergonomic analysis of slipresistance measurement devices. Ergonomics 1985; 28: 1065-1079.

18) Li KW. Development of a slipperiness measurement device to be used in work place. Technical report, National Science Council: 1994 (in Chinese).

19) British Standard Institution. British standard code of practice for stairs. London, 1977. 